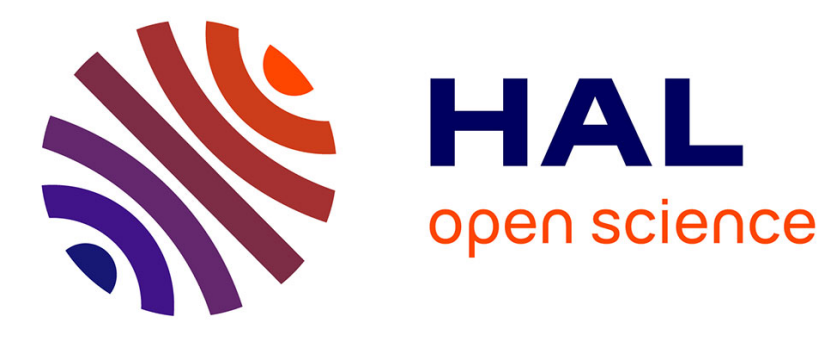

\title{
How can we best monitor 5-FU administration to maximize benefit to risk ratio?
}

Françoise Goirand, Florian Lemaitre, Manon Launay, Camille Tron, Etienne Chatelut, Jean-Christophe Boyer, Marc Bardou, Antonin Schmitt

\section{- To cite this version:}

Françoise Goirand, Florian Lemaitre, Manon Launay, Camille Tron, Etienne Chatelut, et al.. How can we best monitor 5-FU administration to maximize benefit to risk ratio?. Expert Opinion on Drug Metabolism and Toxicology, 2018, 14 (12), pp.1303-1313. 10.1080/17425255.2018.1550484 . hal-01936325

\section{HAL Id: hal-01936325 \\ https://hal-univ-rennes1.archives-ouvertes.fr/hal-01936325}

Submitted on 25 Jan 2019

HAL is a multi-disciplinary open access archive for the deposit and dissemination of scientific research documents, whether they are published or not. The documents may come from teaching and research institutions in France or abroad, or from public or private research centers.
L'archive ouverte pluridisciplinaire HAL, est destinée au dépôt et à la diffusion de documents scientifiques de niveau recherche, publiés ou non, émanant des établissements d'enseignement et de recherche français ou étrangers, des laboratoires publics ou privés. 


\section{How can we best monitor 5FU administration to maximize benefit to risk ratio?}

Françoise Goirand ${ }^{1}$, Florian Lemaitre ${ }^{2}$, Manon Launay ${ }^{3}$, Camille Tron ${ }^{2}$, Etienne Chatelut ${ }^{4}$, Jean-Christophe Boyer ${ }^{5}$, Marc Bardou* ${ }^{6}$ and Antonin Schmitt ${ }^{7}$

${ }^{1}$ Centre Hospitalo-Universitaire de Dijon-Bourgogne, 5 Bd Jeanne d'Arc, 21000 Dijon, France

2 Service de Pharmacologie Clinique, Laboratoire de Pharmacologie Expérimentale et Clinique, Centre d'Investigation Clinique INSERM 1414, CHU de Rennes, Université Rennes 1, 2, rue Henri Le Guilloux, 35000 Rennes, France

${ }^{3}$ Laboratoire de Pharmacologie et de Toxicologie, Service de Pharmacologie, Hôpital Européen Georges Pompidou, 20 rue Leblanc, 75908 Paris Cedex 15, France

${ }^{4}$ Institut Claudius-Regaud et Centre de Recherches en Cancérologie de Toulouse, IUCT Oncopole, lavenue Irène Joliot-Curie, 31059 Toulouse, France

${ }^{5}$ Laboratoire de Biochimie et Biologie Moléculaire, CHU de Nîmes Carémeau, Place du Professeur Robert Debré, 30029 Nîmes Cedex 9, France

${ }^{6}$ Centre d'Investigations Cliniques 1432, Module Plurithématique, CHU Dijon-Bourgogne, Hôpital François Mitterrand, 14, rue Gaffarel, BP77908, 21000 Dijon, France

${ }^{7}$ Service Pharmacie, Centre Georges-François Leclerc, 1 rue Pr. Marion, 21000 Dijon, France

*Corresponding author :

Marc Bardou

Centre d'Investigations Cliniques 1432

Module Plurithématique 


\title{
CHU Dijon-Bourgogne
}

Hôpital François Mitterrand 21000 Dijon

marc.bardou@u-bourgogne.fr

\begin{abstract}
:
Introduction: 5-FU is currently used as a chemotherapy in several cancers such as head-andneck $(\mathrm{H} \& \mathrm{~N})$ and colorectal cancers (CRC). 5-FU dosing is traditionally based on bodysurface-area, but this strategy is usually associated with severe toxicities. 5-FU is mainly catabolized by dihydropyrimidine dehydrogenase (DPD), and 5-FU dosage adaptation according to DPD status at the first cycle of treatment is now recommended. To further optimize 5-FU-based chemotherapy, a body of evidences justifies therapeutic drug monitoring (TDM).
\end{abstract}

Areas covered: 5-FU Pharmacokinetics, relationships between pharmacokinetics and efficacy or toxicity of 5-FU, proofs of interest of 5-FU TDM and its practical considerations are discussed.

Expert opinion: BSA-adjusted 5-FU administration is associated with a large inter-individual variability, and according to this strategy, many patients experience under- or over-exposure. Moreover, relationships between 5-FU area under the curve (AUC) and its toxicity or efficacy have been demonstrated, at least in patients with colorectal or H\&N cancers. 5-FU therapeutic index has been validated and algorithms of 5-FU dosage adaptation according to its AUC are now available. Advances in pre-analytical and analytical steps of 5-FU TDM make its use feasible in clinical practice. Thus, there are consistent evidences to recommend 5-FU TDM in patients with advanced colorectal or $\mathrm{H} \& \mathrm{~N}$ cancers. 
Keywords: 5-fluorouracil, colorectal cancer, head and neck $(\mathrm{H} \& \mathrm{~N})$ cancer, pharmacokinetics, therapeutic drug monitoring (TDM). 


\section{Article highlights}

5-FU pharmacokinetic is characterized by a large inter-individual variability, the main covariates explaining this variability being sex and DPD status. BSA-based dosing methods for 5-FU lead to under- or over-exposure in patients.

5-FU exposure has been correlated to its efficacy and toxicity. In colorectal or head-and-neck cancers, most of the studies describe an optimization of the response when AUC is within the range of 20-30 mg.h/L

Use of 5-FU TDM to achieve 5-FU exposure within the target AUC improves response rate of chemotherapy and reduces the risk of overall grade 3-4 toxicities.

Dose-adjustment algorithms have been published and represent useful tools to longitudinally modify 5 -FU dosage in a same patient.

A recommendation of the International Association of Therapeutic Drug Monitoring and Clinical Toxicology (IATDMCT) strongly supports TDM for the management of 5-FU therapy in patients with colorectal or head-and-neck cancer receiving common 5-FU regimens. 


\section{Introduction}

5-fluorouracil (5-FU) is a cytotoxic drug developed more than 60 years ago and which is still widely used in the treatment of solid tumors such as colorectal cancers, head and neck cancers and breast cancers in neoadjuvant, adjuvant or metastatic settings. 5-FU, as a C5-fluorinated uracil analog, acts as false substrate for tumor DNA and RNA. For this purpose, 5-FU has to be phosphorylated following several anabolic enzymatic reactions. However, the main mechanism leading to 5-FU antitumor effect is the thymidylate synthase inhibition by one of the phosphorylated metabolites (i.e 5-fluorodeoxyuridine) resulting in inbalance in cell nucleotides and finally to an inhibition of DNA synthesis. Besides, most of the 5-FU ( $>80 \%)$ is transformed through dihydropyrimidine deshydrogenase (DPD) metabolizing into inactive components. DPD expression and functionality is highly variable and genetically determined [1]. Thus, the pharmacokinetics of 5-FU can be largely impacted in patients with DPD deficiency leading to severe toxicities such as neutropenia, diarrhea, hand-foot syndromes. These adverse drug reactions are as frequent as $10-30 \%$ and can lead to patient death in around $1 \%$ of cases [2], [3], [4]. As a result, numerous strategies have been developed for dosage adjustment using a pre-therapeutic DPYD genotyping or DPD phenotyping test [3, 5, 6]. These strategies might lead to a dramatic decrease in severe adverse drug reactions. On the opposite, a large proportion of patients are underexposed to 5-FU when applying the usual dosage. [7] It is now highly recognized that 5-FU dosage should be increased in up to $60 \%$ of patients receiving the standard dosage in colorectal cancer treatment [8]. DPD deficiency is, therefore, not the only factor associated with 5-FU concentrations variability [9], [10] and under or overexposure can also occur even in patients whom dosages have been adapted according to their DPD status [11], [12, 13]. In such cases, therapeutic drug monitoring (TDM) of 5-FU plasmatic concentrations appears as a valuable option to ensure an adequate exposure to the drug. Several studies have been conducted on that topic, showing that 5-FU 
presents a narrow therapeutic range and highlighting the clinical interest of the TDM approach [14],[15]. 5-FU prodrugs as capecitabine have also been increasingly used in the past decade. This inactive drug undergoes 3 enzymatic transformations to deliver 5-FU. It has been shown that the two last steps, involving thymidine phosphorylase and uridine phosphorylase and responsible for the conversion to 5-FU, are intense within tumor tissues. In consequence, 5-FU plasmatic concentrations may not be an appropriate marker of 5-FU exposure in case of capecitabine treatment. Moreover, there is very few data concerning capecitabine TDM and this drug and its metabolites plasmatic concentration seem poorly predictive of safety and efficacy [16]. Thus, we focus in the present work, on 5-FU pharmacokinetics, its pharmacokinetic-pharmacodynamic relationships and evidences of 5FU TDM. We also presented in details the practical pre-analytical, analytical and postanalytical processes allowing implementation of 5-FU TDM in clinical practice.

\section{Pharmacokinetics (PK)}

5-FU is a pyrimidine analog and its pharmacokinetics (as well as its pharmacodynamics) properties are related to its structural similarity with uracil. 5-FU is metabolized and transported by protein usually associated with pyrimidine bases; DPD is the major one. DPD is expressed in the hepatocytes as well as in the enterocytes where 5-FU biotransformation is extremely important. Bioavailability of the drug is then considerably decreased preventing it from being orally administered. In spite of this, 5-FU can be administered as an oral prodrug (e.g., capecitabine). Most of 5-FU treatments are based on intravenous infusions with various rate of infusion.

\subsection{Main 5-FU pharmacokinetics properties}

\subsubsection{Distribution:}


5-FU is only marginally bound to plasma proteins with an unbound fraction representing more than $90 \%$ [17]. It can then freely distribute into tissues and cells. The latter involves solute carrier (SLC) transporters, SLC 29A2 and SLC 22A7, and a facilitative transport mechanism. 5-FU is also a substrate for ATP-binding cassette (ABC) transporters (ABCG2, ABCC3, $\mathrm{ABCC} 4$ and $\mathrm{ABCC} 5$ but not P-glycoprotein), which are efflux pumps located at the membrane of several cells and limiting drug entry [18-21]. Higher expression of these transporters have been associated with treatment resistance to 5-FU. Central nervous system penetration of the drug is also limited as is its diffusion into numerous tissues as demonstrated by its low volume of distribution (15 L) [22]. Furthermore, in vitro experiments suggested that 5-FU treatment by itself may up-regulate expression of these transporters, decreasing therefore its own tissue distribution and efficacy [23], [24]. Moreover, administration of 5-FU with others drugs which are substrates of these transporters may modify 5-FU distribution. To our knowledge very little is known concerning 5-FU drugs interactions and consequences of these interactions on 5-FU efficacy and toxicity have to be confirm in in vivo models and in patients, to further understand its clinical impact.

\subsubsection{Metabolism and excretion: (Figure 1)}

As already presented in the introduction, 5-FU undergoes two main ways of biotransformation, anabolic and catabolic pathways. The anabolic pathway, occurring in every cell whether it is normal or tumor cell, leads to the drug anti-cancer effect. The enzymes involved in this way are the same enzymes responsible for the biotransformation of pyrimidine bases. This anabolic pathway resulted in phosphorylated metabolites that can be incorporated to tumor cell DNA or RNA and thus exerts a cytotoxic effect. Among the enzymes of the anabolic pathway, the role of thymidylate synthase has to be underlined as it is 
also a target for 5-FU metabolite fluorodeoxyuridine monophosphate and contributes largely to the drug effect.

5-FU is catabolized by DPD which is a limited step to its elimination process. None of the metabolites produced by this metabolic pathway display any therapeutic effect. 5-FU is extensively metabolized in the liver with a rapid elimination and short half-life of around 10 min. 5-FU clearance is highly variable and several factors contributing to its variability have been reported. Polymorphism in the gene coding for DPD (DPYD) has already been addressed and has been extensively discussed elsewhere $[5,25]$ but age, gender, disease state and organ dysfunction (particularly liver failure) have also been reported to have an impact on 5-FU pharmacokinetics [26] [27, 28]. Absence of correlation between body surface area and 5-FU clearance has been extensively demonstrated [29], [13].

A low amount of 5-FU is eliminated through urinary clearance $(<10 \%)$ and is usually considered as negligible.

\subsection{Non-linearity}

5-FU metabolism into 5-Fluorodihydrouracil (FUH2) follows a saturable process and it as long been a worry for clinicians. In case of 5-FU short-course IV infusions (e.g the bolus infusion part of the FOLFOX or FOLFIRI protocols) the resulting plasma drug concentration is around $30 \mathrm{mg} / \mathrm{L}$. This threshold is far beyond the Michaelis and Menten constant $(\mathrm{Km})$ of DPD (mean value $5.57 \mathrm{mg} / \mathrm{L}$ ) [30], leading to a saturation of DPD and non-linear pharmacokinetics of the drug. During prolonged infusions, the infusion rate is far lower than the mean maximum speed of 5-FU metabolism (Vmax) (e.g $600 \mathrm{mg} / \mathrm{m}^{2}$ during $22 \mathrm{~h}$ for the FOLFOX4 protocol to be compared to a Vmax around $1390 \mathrm{mg} / \mathrm{h}$ ). Plasma concentrations are lower as well as DPD $\mathrm{Km}$ (around $0.2 \mathrm{mg} / \mathrm{L}$ ) and metabolism is then never saturated. Consequently, during prolonged infusion, 5-FU pharmacokinetics can be considered as linear 
which means that in a given patient, steady-state concentrations will vary according to the infusion rate in a proportional manner. The mean clearance of the drug is of $200 \mathrm{~L} / \mathrm{h}$. Apparent half-life during short infusion is also longer than during prolonged infusion as a result of the non-linear pharmacokinetics of the drug.

\subsection{PK variability}

5-FU pharmacokinetics parameters result in an important inter-patient variability. Thus, Gamelin et al. reported a wide range of 5-FU clearance in patients receiving $1300 \mathrm{mg} / \mathrm{m}^{2} / 8 \mathrm{~h}$ with a 10-time exposure variation highlighted [13]. Prolonging the infusion did not conduct to a decrease in variability as a ratio of 25 between lowest and largest value of clearance has been reported during 24h-infusions in patients treated for an ORL cancer [9]. This high variability of drug concentrations was also evidenced recently in a study conducted by Braiteh et al. where area under the curve (AUC) of 5-FU concentrations in patients treated for a colorectal cancer might vary with a ratio up to 12 [10]. Numerous demographic parameters, such as weight and sex, have been reported to influence 5-FU pharmacokinetics although these covariates only explain a small part of the variability of the drug. Saam et al. evaluated 5-FU exposure during FOLFOX6 and FOLFIRI protocols with body surface area (BSA) adjusted dosage. Considering a target of $20-24 \mathrm{mg} . \mathrm{h} / \mathrm{L}$, only $21 \%$ of patients reached the therapeutic range in this study during the first cycle of treatment $(n=357)$. More than $50 \%$ of the patients were underexposed while $27 \%$ of patients displayed concentrations above the upper threshold [7]. Large variability has also been reported in another work including patients treated for a colorectal cancer in which the proposed AUC target was 20-30 mg.h/L. Despite enlarging the exposure target, only $38 \%$ of patients had AUC within the target while again around half (48\%) of the patients were underexposed [10]. 
Because of this large variability in 5-FU pharmacokinetics, BSA-adjusted 5-FU dosing results in very few patients reaching the recommended exposure target.

\section{PK/PD relationships}

\section{1. $\mathrm{PK} /$ side effects}

Historically, in colorectal cancer patients, 5-FU was administered as a bolus over few minutes up to one hour, with doses ranging from 370 to $600 \mathrm{mg} / \mathrm{m}^{2}$. Most frequent serious adverse events were diarrhea (7.1 to $13.6 \%$ ), nausea/vomiting $(23.0 \%)$, leucopenia ( 2.9 à $12.5 \%)$, anemia $(6.2 \%)$, and mucositis $(14.3 \%)[31,32]$.

However, bolus administrations are becoming increasingly marginal, and 5-FU is now mainly administered as continuous infusion. Most of the studies dealing with PK/toxicity relationships in this dosing setting related to colorectal and head and neck (H\&N) cancer patients. Due to the wide range of doses and infusion times, inter-individual variability of drug exposure is thus very important [33] [34]. Main serious side effects encounter during such administrations are diarrhea ( $1.7 \%$ to $13.0 \%)$, mucositis ( 0.8 to $26.0 \%)$, nausea/vomiting (3.7 to $9.4 \%)$, and neutropenia $(7.2$ to $53.0 \%)$ [33, 35-37].

Conflicting results exist concerning the relationship between side effects and 5-FU dosage. Gamelin et al. did not show any relationships between the incidence of toxicity and level of dose increase steps [38], while Blaschke et al. have measured a good correlation between grade 3-4 side effects and 5-FU dosage [39]. However toxicity incidence was significantly correlated with AUC [33, 34, 36, 40, 41] or 5-FU concentrations [38]. Thus, numerous authors have proposed target AUCs to limit toxicity as much as possible, while maximizing efficacy. The most frequent target AUC is the 20 to $25 \mathrm{mg} \cdot \mathrm{h} / \mathrm{L}$ range.

Incidence on toxicity of PK-guided 5-FU dosing (i.e., according to the AUC, with target AUC of 20-25 mg.h/L) compared to BSA-guided dosing has been studied. Rates of 
nausea/vomiting, diarrhea or mucositis were significantly lower in the PK-guided group, contrary to neutropenia which were identical in both groups $[34,40]$. Of note, most of the time, low exposure and good overall tolerance were found in the PK-guided group, explaining the fact that dose was mainly increased [29, 35].

Last, but not least, with higher exposures, women are at higher risk of toxicity when compared to men $[33,34,42]$. However, there is still a lack of understanding on whether this higher toxicity rate in women is linked only to these higher exposures rather than to hypersensitivity to 5-FU effects.

\subsection{PK/efficacy}

PK/efficacy relationships have been less intensively explored than PK/ toxicity relationships. Indeed, due to numerous protocols and to the fact that most of the time 5-FU is not given alone, but as part of a combination, such as FOLFIRI or FOLFOX, studies are hardly comparable. However, some authors have tried to evidence those relationships. The first to do so were Hillcoat et al., in 1978, who demonstrated, in 27 colorectal adenocarcinoma patients treated with $1000-2000 \mathrm{mg} / \mathrm{m}^{2} /$ day of 5 -FU for 5 days (associated for some of them to methyl-CCNU), that responding patients had a mean AUC of 36 mg.h/L, whereas nonresponding patients had a mean AUC of 19.2 mg.h/L [43]. In 1996, Gamelin et al. have reported, in advanced colorectal cancer patients treated with a weekly 5-FU 8h-infusion, that responding patients experienced higher 5-FU concentrations than non-responding ones [38]. Moreover, one-year survival was higher in patients with 5-FU concentrations above the mean concentration $(70.6 \%)$, whereas survival was lower, although not reaching statistical significance, in patients with 5-FU concentration below the mean (46\%).

The PK/efficacy relationship is of particular relevance in 5-FU continuous infusion over 2 days protocols, as it is nowadays the standard of care. In 2003, Ychou et al. demonstrated the 
interest of a PK-guided dosing, in first or second line treatment in 53 colorectal adenocarcinoma patients [37]. These patients were treated by de Gramont modified LV5FU2 [44] and 4 PK samples were drawn during the 2 days of infusion in order to adapt the dose at the next cycle. Response rate was of $37 \%$, i.e., higher than the $33 \%$ published in the original de Gramont study [45]. For patients receiving 5-FU as a first line therapy, progression free survival and overall survival were respectively of 7.6 and 19.2 months, results very close to those observed when 5-FU was given in association with oxaliplatin or irinotecan.

To the best of our knowledge, no study has evaluated PK/efficacy relationships during polychemotherapies where 5-FU is associated to oxaliplatin and/or irinotecan. However, some interesting results could be sort out of 2012 Captain's phase II study [35]. In this study, FOLFOX treated patients were randomly assigned to either a BSA-dosed group or a PKguided dosed group. Even if Captain et al. did not clearly point out the link between exposure and efficacy, they show that PK-guided patients received higher doses than BSA patients and that 3-months response rate, progression free survival and overall survival were higher in the PK-guided group.

A recent study also demonstrates PK/efficacy relationships in Asian nasopharyngeal carcinoma patients treated with 5-FU and cisplatin combination [36]. Ma et al. have shown that patients with an AUC $<25 \mathrm{mg} \cdot \mathrm{h} / \mathrm{L}$ presented a $17.5 \%$ lower response rate than patients with an AUC between 25 and $35 \mathrm{mg} \cdot \mathrm{h} / \mathrm{L}$ and $26.1 \%$ lower than patients with an AUC > 35 $\mathrm{mg} \cdot \mathrm{h} / \mathrm{L}$. This study is, to our knowledge, the only one to prove this relationship in $\mathrm{H} \& \mathrm{~N}$ patients.

4. Therapeutic drug monitoring contribution in clinical studies

\subsection{Background}


Once the demonstration made that there is on the one hand a large variability of 5-FU plasmatic concentrations and on the other hand a link between these latter concentrations and their therapeutic and/or toxic effects, it is important to assess the impact that TDM of 5-FU could have on its clinical use. The aim of the present chapter is to evaluate the impact of the TDM in concentration-controlled studies in terms of risk reduction of unexpected adverse effects, as well as, a way of optimizing treatment efficacy.

\subsection{Retrospective controlled-concentration studies}

Several retrospective works tried to compare therapeutic or adverse effects observed between patient groups benefiting or not from a TDM-guided dose adjustment. In H\&N cancers treated with 5-FU continuous infusion at the dose of $1000 \mathrm{mg} / \mathrm{m}^{2}$ /day during 5 days, the dose adjustment based on an AUC target during the first 3 days, led to a reduction of hematological and digestive adverse events without decreasing treatment response [46]. Several other retrospective studies carried out in the colorectal cancer field have shown that patients treated with 5-FU were frequently below the target AUC. Without TDM dose adjustment, only a small percentage of patients (less than one out of four patients) reached an objective of AUC 0-8h between 20 and $24 \mathrm{mg} . \mathrm{h} / \mathrm{L}$ [7]. After 1 to 2 TDM dose adjustments, target AUC was met in $2 / 3$ of the patients, while 3 or 4 dose adjustments were required for the other $1 / 3$ of patients $[10,47]$

\subsection{Prospective studies}

The first prospective concentration-controlled study has been conducted in 1989 by Santini et al. [48]. The authors reported, in patients treated with $5-\mathrm{FU}$ infusions of $1000 \mathrm{mg} / \mathrm{m}^{2} /$ day during 5 days for $\mathrm{H} \& \mathrm{~N}$ cancer $(\mathrm{n}=81)$, a target $\mathrm{AUC}_{0-105 \mathrm{~h}}$ of $15 \mathrm{mg} \cdot \mathrm{h} / \mathrm{L}$ allowing a reduction of moderate and severe 5-FU toxicities from $20 \%$ to $12.4 \%$, while increasing therapeutic 
response from $31 \%$ to $47 \%$. A randomized multicenter study in $H \& N$ cancer $(n=106)$ has confirmed the benefit of TDM in preventing adverse events [41]. In this study, patients were randomized to receive 5-FU (in combination with cisplatin) adapted either on BSA or on calculated AUC. Efficacy was similar between the two arms of treatment but severe adverse events (neutropenia, thrombopenia and mucosis) were significantly less frequent in the TDMguided arm.

In the metastatic colorectal cancer field, targeting an AUC of 16 to $24 \mathrm{mg} \cdot \mathrm{h} / \mathrm{L}$ in patients treated with an initial dose of $1300 \mathrm{mg} / \mathrm{m}^{2}$ of 5 -FU infused over $8 \mathrm{~h}$, allowed high rates of patient survival at 1 year (71\%) and 2 years (35\%) [49]. These results have been confirmed by Ychou et al. in patients treated with $400 \mathrm{mg} / \mathrm{m}^{2}$ of $5-\mathrm{FU}$ during two days followed by a continuous infusion of $600 \mathrm{mg} / \mathrm{m}^{2}$ for $22 \mathrm{~h}$. Patients benefited from dosage adjustments to reach an AUC > $20 \mathrm{mg} . \mathrm{h} / \mathrm{L}$, resulting in $37 \%$ of objective response and a 2 -year overall survival of $32 \%$, while safety profile remains favorable [37]. In 2012, Capitain et al. conducted a prospective study to evaluate efficacy and safety of a TDM-guided treatment (target $\mathrm{AUC}_{0-8 \mathrm{~h}}=20-24 \mathrm{mg} . \mathrm{h} / \mathrm{L}$ ) in patients treated with an initial dose of $2500 \mathrm{mg} / \mathrm{m}^{2}$ during 46h [35]. In this study, 118 patients in the TDM-guided arm have been compared to 39 patients whom dosage has been calculated on the basis of BSA. TDM allowed increasing overall survival duration (38.2 versus 16.6 months), while dramatically decreasing grade 3 and 4 adverse events with a $25 \%$ drop in neutropenia, $86 \%$ in diarrhea, and $95 \%$ in mucositis. These outstanding results have been again confirmed in 2014 and in 2016 by Patel et al. and Wilhem et al. respectively. These authors compared in 75 patients a 5-FU TDM-guided FOLFOX, FUFOX or AIO protocols with a target AUC of $20-30 \mathrm{mg} . \mathrm{h} / \mathrm{L}$ to historical data, and reported a reduction of nausea (by 44\%), diarrhea (by 69\%), neutropenia (by 85\%), mucositis (by 96\%) and fatigue and weakness episodes (by 100\%) [34, 50]. 
Definitive confirmation of the role of TDM in 5-FU dose adjustment came from the randomized multicenter study conducted by Gamelin et al. 2008 [15]. In this study aiming at comparing 5-FU TDM-guided infusion (with a target of AUC $_{0-8 \mathrm{~h}}$ of $20-25 \mathrm{mg} \cdot \mathrm{h} / \mathrm{L}$ ) to BSAcalculated dose (on the basis of $1500 \mathrm{mg} / \mathrm{m}^{2} / 8 \mathrm{~h}$ once a week) ( $\mathrm{n}=186$ ), the objective response was higher in the TDM-guided arm (34\% vs $18 \%)$ and adverse events were more frequent in the BSA-adapted arm.

5. Practical considerations for 5FU-TDM

5.1. May we chronomodulate 5FU perfusion?

The within-day concentrations variations of 5-FU when administered as a continuous infusion, is associated with the circadian rhythm of DPD activity. The DPD has a peak of activity during the night around $1 \mathrm{a} . \mathrm{m}$. and its minimum of activity is observed around 1 p.m. [51].

Studies have attempted to optimize 5-FU efficacy considering circadian variations in DPD activity. In a phase II study where patients were treated for colorectal cancer with FOLFOX regimen, Levi et al. [52] compared the efficacy of "chronomodulated" regimen to the standard fixed-infusion-rate delivery. The perfusion rate of 5-FU was maximal at 4 a.m. in the morning, and the oxaliplatin one was maximal at 4 p.m. These authors showed a reduction in toxicity and an improvement in efficacy in the group of patients whose administration was chronomodulated.

However, the benefit and the feasibility of the chronomodulated therapy have been questioned many times. Indeed, although the existence of a circadian rhythm in 5-FU drug levels is largely accepted, it remains that the positioning of the peak and residual concentrations, as 
well as the amplitude of variation between both of them are extremely variable. Moreover, they depend on the dose of 5-FU administered and on the chemotherapy protocol.

Conflicting data exist between the rhythms of DPD activity and consequently the circulating levels of uracil and dihydrouracil. Many endogenous or exogenous factors such as sex, food intake, exposure to light, body temperature, physical activity or interaction with other enzymes or mediators have been suggested as potential modulators of the activity of the DPD [53]. In a phase III randomized clinical trial conducted in patients with metastatic colorectal cancer, Giacchetti et al [54] compared a 4-day chronomodulated administration (chronoFLO4) with the conventional 2-day delivery (FOLFOX2) on tolerability and anticancer activity. The results of this study showed that both tolerability and efficacy response rates were similar whatever the treatment modalities. However, a strong sex dependence of efficacy and tolerability of the treatment was observed, as chronomodulated administration produced a survival advantage in men but decreased the medial survival time in women. Until now, chronomodulated administration of 5-FU does not seem to be applicable in current clinical practice.

5.2. When drawing sampling and how many samples are needed to calculate 5-FU AUC?

In several studies conducted in 5-FU-treated patients for H\&N cancer by a 96 or $120 \mathrm{~h}$ continuous infusion, 5-FU concentration was measured two times per $24 \mathrm{~h}$ of infusion to calculate the AUC $[41,48,55,56]$.

In colorectal cancer patients, 5-FU treatment consists in a $4 \mathrm{~h}$ to $46 \mathrm{~h}$ infusion preceded or not by a bolus. In order to investigate the 5-FU exposition-efficacy and exposition-toxicity relationships in CRC patients receiving weekly 8 h-infusion of 5-FU, Gamelin et al. calculated 5-FU AUC from two blood samples taken at the $4^{\text {th }}$ and $8^{\text {th }}$ hour of every 5-FU 
infusion [38, 49]. This sampling strategy was justified by an observed higher 5-FU concentration at the end of the perfusion than at the middle. The mechanism involved is known. 5-FU slows down its own catabolism by inhibiting DPD, the rate-limiting enzyme in 5-FU catabolism.

In several US-studies testing a PK-guided 5-FU dosing in CRC patients treated every two weeks by a $44 \mathrm{~h}$ or $46 \mathrm{~h}$ infusion, blood samples were collected at least $2 \mathrm{~h}$ after the start of the infusion and before the end [7, 34].

However in CRC patients receiving any regimen in which 5-FU was administrated over a period of $46 \mathrm{~h}$, AUC was often evaluated from a single blood sample taken between $18 \mathrm{~h}$ and $26 \mathrm{~h}$ after the start of the infusion $[47,57,58]$. Kaldate et al. have evaluated the effects of the sample collection time on AUC measurements, in order to optimize blood sampling time for PK analysis [57]. They showed a lower mean AUC value when the blood sample was drawn in the early hours of the infusion (2 hours). However AUC values were not different when calculated from concentrations of samples drawn at $22 \mathrm{~h}$ or $44 \mathrm{~h}$ infusion. Thus, an adequate strategy may be to wait the 5-FU plasma concentration steady-state before drawing the sample, which occurred theoretically 2-hours after the start of perfusion. Moreover, the sample should probably be drawn at the same time in the day to decrease the blood level fluctuations due to 5-FU chronopharmacokinetics. Morawska et al. used this collection strategy, drawing blood samples each morning between 08.00 and 10.00 a.m., the infusion having begun the day before [29].

5-FU can be administered by portable diffusers. In this case, it should be noted that the portable diffusers used have a $+/-15 \%$ flow variation tolerance with respect to the nominal flow rate and it has been shown that its performances may fluctuate depending on atmospheric conditions, pressure and temperature [59] [60]. Although this flow rate variation has no impact on the entire dose received by the patient, it leads to additional inaccuracy in 
the measurement of 5-FU concentrations as a function of the sampling time. The use of infusion pumps (i.e., whose flow rate is controlled) limits this bias but often requires hospitalization of the patient.

\subsection{Challenges in the pre-analytical stage}

5-FU is extremely unstable in whole blood, due to the presence in bloods cells of the 5-FU, catabolic enzyme DPD that rapidly transform 5-FU in dihydro-5FU, its inactive metabolite. To limit this enzymatic degradation, it is recommended to place on ice the sample immediately, and to centrifuge the blood as quickly as possible after sampling. Several maximal delays between sampling and centrifugation have been proposed. Whereas BoisdronCelle et al. [61] recommended a maximum delay of 2 hours between sampling and centrifugation, Morawska et al. [29] proposed to centrifuge the blood sample within $30 \mathrm{~min}$ after collection. Indeed, these authors observed a decrease in concentrations of about $25 \%$ between samples centrifuged in the hour versus those centrifuged within $30 \mathrm{~min}$ after collection. After centrifugation, little variation in 5-FU plasma concentration is noted. A plasma sample frozen at $-20^{\circ} \mathrm{C}$ is stable for several weeks [62].

5-FU concentrations can be stabilized by adding immediately after sampling a stabilizing reagent in the blood. It is a derivative of uracil, gemiracil, which inhibits DPD [34]. It is presented as a ready-to-use solution to be injected through the cap of the sample tube directly into the sample after its collection. After using this stabilizer, the sample should not be refrigerated and can be centrifuged within 24 hours after inhibitor addition. (Table 2)

\subsection{5-FU TDM assays}

HPLC is the most widely used method to quantitate 5-FU in clinical settings [63]. Several different HPLC methods have been developed with limits of detection within the range of 6 - 
$150 \mathrm{ng} / \mathrm{mL}$. More recently, most sophisticated Liquid chromatography - tandem mass spectrometry (LC-MS/MS) have been validated. LC-MS/MS methods exhibit very low limit of detection and quantification. In case of treatment by a 5-FU prodrug like capecitabine, LCMS/MS methods have been developed to simultaneously quantitate the prodrug and its active metabolites 5'-desoxy-5-fluorouridine (5'-DFUR) and 5-FU [64, 65], but also uracil and dihydrouracil [66]. Thereby some LC-MS/MS methods make it possible to perform both the recommended DPD phenotyping (as dihydro-uracil / uracil ratio) before the first 5-FU course to prevent major toxicity [5], and 5-FU quantitation after the treatment.

A homogenous nanoparticule immunoassay based on turbidimetry and the use of a novel monoclonal antibody selective for 5-FU has also been developed (My5-FU ${ }^{\mathrm{TM}}$ ). Lower limit of quantitation is generally described around $85 \mathrm{ng} / \mathrm{ml}$ [67]. Cross-reactivity of antibodies to 5FU was less than $1 \%$ for dihydro-5-FU, capecitabine, and tegafur but $11 \%$ for uracil. However a comparison between this immunoassay and LC-MS/MS was performed by Beumer et al. [67] using samples collected from 156 patients receiving 5-FU therapy for colorectal or H\&N cancers. Immunoassay results of clinical samples correlated well with the validated LC/MS-MS results (93-1774 $\mathrm{ng} / \mathrm{mL}$ by immunoassay vs $79-1791 \mathrm{ng} / \mathrm{mL}$ by LC/MS-MS, high correlation coefficient $=0.98$ ).

\subsection{Cost of 5-FU TDM}

In a time of increasing concerns regarding the cost of cancer care, there are many examples of personalized medicine producing cost savings. Treatment of 5-FU induced severe toxicity is usually associated with discontinuation of anticancer therapy and often requires hospitalization or induces extension of hospital stays. Consequently, in addition to having a great impact on a patient's prognosis and quality of life, treatment toxicity can also result in significant increase in health care costs. Hence, decreasing toxicities ensured by the 
pharmacokinetically-guided dosage adjustment might decrease the additional cost associated with these adverse events (mainly hospital stay prolongation). This hypothesis was supported by two publications that have shown in patients treated for metastatic CRC that 5-FU doseadjustment according to 5-FU plasma concentration was cost-effective in comparison with BSA dosing $[68,69]$. However, these results come from simulations of the cost-effectiveness of pharmacokinetically-based versus BSA-based dosing of 5-FU. Thus, to our knowledge, furthers prospective studies on the economic impact of 5-FU pharmacokinetics-guided dosing have to be conducted.

\section{Scientific societies positioning}

Based on the fact that DPD activity can predict 5-FU levels and its toxicity, the French National Agency for the Safety of Medicines and Health Products (ANSM) recommends the preventive screening for deficits in DPD activity before the start of treatment. The text describes the techniques available for this screening, DPYD genotyping or DPD phenotyping, without prioritizing one or the other. These recommendations are based on a publication of the "Groupe de Pharmacologie Clinique Oncologique" (GPCO)-UNICANCER [5].

Concerning 5-FU TDM, very recent recommendations have been published by a working group of the International Association of Therapeutic Drug Monitoring and Clinical Toxicology (IATDMCT). Based on an extensive literature review, the authors have summarized all the data justifying TDM of 5-FU therapy and in conclusion strongly recommend TDM for the management of 5-FU therapy in patients with $\mathrm{H} \& \mathrm{~N}$ and advanced colorectal cancer [70].

\section{Conclusion}


To conclude, in the context of 5-FU continuous infusions for the treatment of colorectal and head and neck cancer, we recommend pharmacokinetically-guided 5-FU dosage adjustment, using a single 5-FU concentration measured at steady-state concentrations, and a target AUC of 20-30 mg.h/L. This approach is appropriate to optimize 5-FU dose intensity and improve clinical outcome by reducing toxicity and improving efficacy.

\section{Expert opinion on 5FU TDM}

Contribution of 5-FU TDM appears unquestionable in the light of literature data. Dosage adaptations based on BSA are associated with a large variability in drug exposure and thus seem unsuitable because of the risk of severe side effects or jeopardize efficacy. It should be noted that two randomized controlled studies demonstrated the superiority of dosage adjustment based on 5-FU TDM in comparison with BSA: one in H\&N cancer and the other in metastatic colorectal cancer. Furthermore, several prospective comparative studies have shown the interest of monitoring 5-FU concentrations in terms of improving efficacy and reducing the occurrence of adverse events. In the light of these data, the lack of dosage adaptation as a function of plasma concentrations is a loss of opportunity for patients. Evaluation of 5-FU AUC allows toxicity reduction, but also dose increasing and stabilizing concentrations within the therapeutic range.

The strategy of pharmacokinetically-guided dose adaptation did not compete with DPYD genotyping or DPD phenotyping approaches; they are complementary, DPD status being recommended to be evaluated before the first 5-FU administration, and 5-FU TDM being recommended during the first and subsequent treatment cycles. We recommend to determine DPD deficiency by measuring serum uracil concentration, as it evaluate all sources of DPD deficiency (any DPYD variants or deficiency due to any other cause) in order to avoid severe toxicity associated with first administration, while 5-FU TDM ensures sufficient exposure if 
the impact of the deficiency was to be overestimated. Moreover, TDM helps to adapt dose in patients without any DPD deficiency.

As the drug can be extremely promptly degraded in the blood due to DPD-induced catabolism, centrifuging the samples maximally 30 minutes after sampling is a simple method to overcome that issue; another way is to add a DPD inhibitor to the sample. Commercial solutions to this problem are now available. A DPD inhibitor is included in the immunoassay kits. It can also be obtained separately and used to stabilize samples before assay by analytical methods including chromatography. We believe that the resolution of this limiting preanalytical issue should result in an increase in 5-FU dosing laboratories and thus in the number of patients who may benefit from it. Despite these improvements in terms of management of the pre-analytical steps, it remains important to follow certain precautions mentioned in Table 2.

Currently, there are three methods to dose 5-FU: traditional HPLC-UV, still widely used, LCMSMS assays, development of which being adapted to laboratories specialized in TDM with highly degree specialized staff, and an immunoassay technique. The latter technology provides advantages in terms of shorter time-to-result for clinical samples, minimal sample handling, and ready application on automated instrumentations. Thus, this technology makes 5-FU testing available for routine clinical practice, despite its cost, which is much higher than that of an HPLC assay. However, the test remains to be adapted to a larger number of analyzers.

AUC has been demonstrated to be the appropriate PK parameter correlated to 5-FU toxicity or efficacy. AUC is easily determined by multiplying 5-FU plasma steady-state concentration by infusion duration. As a consequence of its short half-life and circadian variations, we recommend at last a 4-hours delay after the beginning of 5-FU infusion for the collection, and that sample timing should be the same at each cycle for a given patient to limit intra- 
individual variability. Once 5-FU concentration is determined and AUC calculated, we propose, in Table 2, an algorithm to select the percent of dose increase or decrease. Because of its intrinsic variability, maintaining exposure within such a narrow therapeutic window as the one proposed by Gamelin [15] is challenging; thus, an AUC range of $20-30 \mathrm{mg} . \mathrm{h} / \mathrm{L}$ is considered sufficient for successful therapy and dose can be increased or decreased by up to $30 \%$. However, as 5-FU is dosed, most of the time, concomitantly with other cytotoxic drugs or biotherapies, in case of side effects, one should always evaluate the implication of other drugs and adapt their dose if necessary.

In the coming years, a global approach, via an algorithm taking into account DPD deficiency, 5-FU concentrations, patients, disease and tumor characteristics is necessary to optimize patients' treatment. At the time of real-word data and machine learning, the developed algorithm should allow an adaptation of doses during the entire treatment time course and should be updated frequently in the light of the routinely collected biological and clinical data.

\section{Funding}

This paper was not funded.

\section{Declaration of interest}

The authors have no relevant affiliations or financial involvement with any organization or entity with a financial interest in or financial conflict with the subject matter or materials discussed in the manuscript. This includes employment, consultancies, honoraria, stock ownership or options, expert testimony, grants or patents received or pending, or royalties.

\section{Reviewer disclosures}

Peer reviewers on this manuscript have no relevant financial or other relationships to disclose. 
Figures legends:

Figure 1 : Metabolic pathways and therapeutic targets of 5-FU and its metabolites.

Figure 2 : Relationship between 5-FU plasma concentrations and 5-FU continuous infusion dose at cycle 1 of treatment.

Data taken from Morawska et al [29]. 
References

Papers of special note have been highlighted as:

- of interest

•• of considerable interest

1. van Kuilenburg AB. Dihydropyrimidine dehydrogenase and the efficacy and toxicity of 5fluorouracil. Eur J Cancer. 2004;40:939-950.

2. Tsalic M, Bar-Sela G, Beny A, et al. Severe toxicity related to the 5fluorouracil/leucovorin combination (the Mayo Clinic regimen): a prospective study in colorectal cancer patients. Am J Clin Oncol. 2003;26:103-106.

3. Meulendijks D, Henricks LM, Jacobs BAW, et al. Pretreatment serum uracil concentration as a predictor of severe and fatal fluoropyrimidine-associated toxicity. $\mathrm{Br} \mathrm{J}$ Cancer. 2017;116:1415-1424.

4. Marques RP, Duarte GS, Sterrantino C, et al. Triplet (FOLFOXIRI) versus doublet (FOLFOX or FOLFIRI) backbone chemotherapy as first-line treatment of metastatic colorectal cancer: A systematic review and meta-analysis. Crit Rev Oncol Hematol. 2017;118:54-62.

5. Loriot MA, Ciccolini J, Thomas F, et al. [Dihydropyrimidine dehydrogenase (DPD) deficiency screening and securing of fluoropyrimidine-based chemotherapies: Update and recommendations of the French GPCO-Unicancer and RNPGx networks]. Bull Cancer. 2018;105:397-407.

6. Meulendijks D, Cats A, Beijnen $\mathrm{JH}$, et al. Improving safety of fluoropyrimidine chemotherapy by individualizing treatment based on dihydropyrimidine dehydrogenase activity - Ready for clinical practice? Cancer Treat Rev. 2016;50:23-34. 
- Extensive review describing strategies available to identify patients at risk of developing severe and potentially fatal toxicities as a result of DPD deficiency

7. Saam J, Critchfield GC, Hamilton SA, et al. Body surface area-based dosing of 5fluoruracil results in extensive interindividual variability in 5-fluorouracil exposure in colorectal cancer patients on FOLFOX regimens. Clin Colorectal Cancer. 2011;10:203206.

- Key study describing the extensive interindividual variability in 5-FU exposure in case of BSA-based dosing

8. Kunzmann V, Link $\mathrm{K}$, Miller $\mathrm{MC}$, et al. A prospective, multi-center study of individualized, pharmacokinetically (PK)-guided dosing of 5-fluorouracil (5-FU) in metastatic colorectal cancer (mCRC) patients treated with weekly or biweekly 5FU/oxaliplatin containing regimens. Journal of Clinical Oncology. 2015;33.

9. Milano G, Etienne MC, Cassuto-Viguier E, et al. Influence of sex and age on fluorouracil clearance. J Clin Oncol. 1992;10:1171-1175.

10. Braiteh FS, Salamone SJ, Li YY, et al. Pharmacokinetic (PK)-guided optimization of 5fluorouracil $(5 \mathrm{FU})$ exposure in colorectal cancer (CRC) patients: USbased clinical practices experience. Journal of Clinical Oncology. 2014;32.

11. Undevia SD, Gomez-Abuin G, Ratain MJ. Pharmacokinetic variability of anticancer agents. Nat Rev Cancer. 2005;5:447-458.

12. Saif MW, Choma A, Salamone SJ, et al. Pharmacokinetically guided dose adjustment of 5-fluorouracil: a rational approach to improving therapeutic outcomes. J Natl Cancer Inst. 2009; 101:1543-1552.

13. Gamelin E, Boisdron-Celle M, Guerin-Meyer V, et al. Correlation between uracil and dihydrouracil plasma ratio, fluorouracil (5-FU) pharmacokinetic parameters, and tolerance in patients with advanced colorectal cancer: A potential interest for predicting 5-FU toxicity and determining optimal 5-FU dosage. J Clin Oncol. 1999;17:1105. 
14. Andre T, Quinaux E, Louvet C, et al. Phase III study comparing a semimonthly with a monthly regimen of fluorouracil and leucovorin as adjuvant treatment for stage II and III colon cancer patients: final results of GERCOR C96.1. J Clin Oncol. 2007;25:3732-3738.

15. Gamelin E, Delva R, Jacob J, et al. Individual fluorouracil dose adjustment based on pharmacokinetic follow-up compared with conventional dosage: results of a multicenter randomized trial of patients with metastatic colorectal cancer. J Clin Oncol. 2008;26:2099-2105.

-• Prospective randomized clinical trial that has investigated in patients with advanced CRC the value of 5-FU TDM compared to BSA-based dosing.

16. Gieschke R, Burger HU, Reigner B, et al. Population pharmacokinetics and concentration-effect relationships of capecitabine metabolites in colorectal cancer patients. Br J Clin Pharmacol. 2003;55:252-263.

17. Zhang J, Zhang L, Yan Y, et al. Are capecitabine and the active metabolite 5-Fu CNS penetrable to treat breast cancer brain metastasis? Drug Metab Dispos. 2015;43:411-417.

18. Hagmann W, Faissner R, Schnolzer M, et al. Membrane drug transporters and chemoresistance in human pancreatic carcinoma. Cancers (Basel). 2010;3:106-125.

19. Kool M, de Haas M, Scheffer GL, et al. Analysis of expression of cMOAT (MRP2), MRP3, MRP4, and MRP5, homologues of the multidrug resistance-associated protein gene (MRP1), in human cancer cell lines. Cancer Res. 1997;57:3537-3547.

20. Yuan J, Lv H, Peng B, et al. Role of BCRP as a biomarker for predicting resistance to 5fluorouracil in breast cancer. Cancer Chemother Pharmacol. 2009;63:1103-1110.

21. Yuan JH, Cheng JQ, Jiang LY, et al. Breast cancer resistance protein expression and 5fluorouracil resistance. Biomed Environ Sci. 2008;21:290-295.

22. Schaaf LJ, Dobbs BR, Edwards IR, et al. Nonlinear pharmacokinetic characteristics of 5fluorouracil (5-FU) in colorectal cancer patients. Eur J Clin Pharmacol. 1987;32:411-418. 
23. Oguri T, Bessho Y, Achiwa H, et al. MRP8/ABCC11 directly confers resistance to 5fluorouracil. Mol Cancer Ther. 2007;6:122-127.

24. Nambaru PK, Hubner T, Kock K, et al. Drug efflux transporter multidrug resistanceassociated protein 5 affects sensitivity of pancreatic cancer cell lines to the nucleoside anticancer drug 5-fluorouracil. Drug Metab Dispos. 2011;39:132-139.

25. Caudle KE, Thorn CF, Klein TE, et al. Clinical Pharmacogenetics Implementation Consortium guidelines for dihydropyrimidine dehydrogenase genotype and fluoropyrimidine dosing. Clin Pharmacol Ther. 2013;94:640-645.

26. Stein BN, Petrelli NJ, Douglass HO, et al. Age and sex are independent predictors of 5fluorouracil toxicity. Analysis of a large scale phase III trial. Cancer. 1995;75:11-17.

27. Ansfield FJ, Schroeder JM, Curreri AR. Five years clinical experience with 5fluorouracil. JAMA. 1962;181:295-299.

28. Fleming RA, Milano GA, Etienne MC, et al. No effect of dose, hepatic function, or nutritional status on 5-FU clearance following continuous (5-day), 5-FU infusion. Br $\mathrm{J}$ Cancer. 1992;66:668-672.

29. Morawska K, Goirand F, Marceau L, et al. 5-FU therapeutic drug monitoring as a valuable option to reduce toxicity in patients with gastrointestinal cancer. Oncotarget. 2018;9:11559-11571.

30. Terret C, Erdociain E, Guimbaud R, et al. Dose and time dependencies of 5-fluorouracil pharmacokinetics. Clin Pharmacol Ther. 2000;68:270-279.

31. Grem JL, Quinn M, Ismail AS, et al. Pharmacokinetics and pharmacodynamic effects of 5-fluorouracil given as a one-hour intravenous infusion. Cancer Chemother Pharmacol. 2001;47:117-125. 
32. Ismail AS, Quinn MG, Wright MA, et al. A phase II and pharmacologic study of fluorouracil given by a 1-hour infusion daily for 5 days with leucovorin and interferon alpha-2a in adenocarcinoma of the large bowel. Oncol Rep. 2005;13:1145-1152.

33. Gusella M, Crepaldi G, Barile C, et al. Pharmacokinetic and demographic markers of 5fluorouracil toxicity in 181 patients on adjuvant therapy for colorectal cancer. Ann Oncol. 2006;17:1656-1660.

34. Patel JN, O'Neil BH, Deal AM, et al. A community-based multicenter trial of pharmacokinetically guided 5-fluorouracil dosing for personalized colorectal cancer therapy. Oncologist. 2014;19:959-965.

35. Capitain O, Asevoaia A, Boisdron-Celle M, et al. Individual fluorouracil dose adjustment in FOLFOX based on pharmacokinetic follow-up compared with conventional body-areasurface dosing: a phase II, proof-of-concept study. Clin Colorectal Cancer. 2012;11:263267.

- One of the first studies showing superiority of PK-guided 5-FU dosage toward BSAguided dosage on progression free and overall survival in metastatic CRC patients

36. Ma Y, Lin Y, Zou B, et al. Pharmacokinetic and Pharmacodynamic Analyses of 5Fluorouracil in East-Asian Patients with Nasopharyngeal Carcinoma. Clin Pharmacokinet. 2016;55:1205-1216.

37. Ychou M, Duffour J, Kramar A, et al. Individual 5-FU dose adaptation in metastatic colorectal cancer: results of a phase II study using a bimonthly pharmacokinetically intensified LV5FU2 regimen. Cancer Chemother Pharmacol. 2003;52:282-290.

38. Gamelin EC, Danquechin-Dorval EM, Dumesnil YF, et al. Relationship between 5fluorouracil (5-FU) dose intensity and therapeutic response in patients with advanced colorectal cancer receiving infusional therapy containing 5-FU. Cancer. 1996;77:441451. 
39. Blaschke M, Cameron S, Goeschen C, et al. 5-FU schedules, serum 5-FU levels and their relationship to therapy response and toxicity in patients with gastrointestinal cancer. Int $\mathbf{J}$ Clin Pharmacol Ther. 2013;51:56-58.

40. Special report: laboratory testing to allow area under the curve (AUC)-targeted 5fluorouracil dosing for patients administered chemotherapy for cancer. Technol Eval Cent Assess Program Exec Summ. 2010;24:1-3.

41. Fety R, Rolland F, Barberi-Heyob M, et al. Clinical impact of pharmacokineticallyguided dose adaptation of 5-fluorouracil: results from a multicentric randomized trial in patients with locally advanced head and neck carcinomas. Clin Cancer Res. 1998;4:20392045.

- Prospective randomized clinical trial that has investigated, in patients with $H \& N$ cancer, the value of 5-FU TDM compared to BSA-based dosing

42. Woloch C, Di Paolo A, Marouani H, et al. Population pharmacokinetic analysis of 5-FU and 5-FDHU in colorectal cancer patients: search for biomarkers associated with gastrointestinal toxicity. Curr Top Med Chem. 2012;12:1713-1719.

43. Hillcoat BL, McCulloch PB, Figueredo AT, et al. Clinical response and plasma levels of 5-fluorouracil in patients with colonic cancer treated by drug infusion. $\mathrm{Br} \mathrm{J}$ Cancer. $1978 ; 38: 719-724$.

44. de Gramont A, Bosset JF, Milan C, et al. Randomized trial comparing monthly low-dose leucovorin and fluorouracil bolus with bimonthly high-dose leucovorin and fluorouracil bolus plus continuous infusion for advanced colorectal cancer: a French intergroup study. J Clin Oncol. 1997; 15:808-815.

45. de Gramont A, Figer A, Seymour M, et al. Leucovorin and fluorouracil with or without oxaliplatin as first-line treatment in advanced colorectal cancer. J Clin Oncol. 2000;18:2938-2947. 
46. Wihlm J, Leveque $\mathrm{D}$, Velten $\mathrm{M}$, et al. [Pharmacokinetic monitoring with dosage adjustment of 5 fluorouracil administered by continuous infusion]. Bull Cancer. 1993;80:439-445.

47. Kline CL, Sheikh HS, Scicchitano A, et al. Preliminary observations indicate variable patterns of plasma 5-fluorouracil (5-FU) levels during dose optimization of infusional 5FU in colorectal cancer patients. Cancer Biol Ther. 2011;12:557-568.

48. Santini J, Milano G, Thyss A, et al. 5-FU therapeutic monitoring with dose adjustment leads to an improved therapeutic index in head and neck cancer. $\mathrm{Br} \mathrm{J}$ Cancer. 1989;59:287-290.

49. Gamelin E, Boisdron-Celle M, Delva R, et al. Long-term weekly treatment of colorectal metastatic cancer with fluorouracil and leucovorin: results of a multicentric prospective trial of fluorouracil dosage optimization by pharmacokinetic monitoring in 152 patients. $\mathrm{J}$ Clin Oncol. 1998;16:1470-1478.

- Key study showing in CRC patients that TDM-guided 5-FU dosage with an AUC target of 16-24 mg.h/L is associated with high rate patient survival

50. Wilhelm M, Mueller L, Miller MC, et al. Prospective, Multicenter Study of 5Fluorouracil Therapeutic Drug Monitoring in Metastatic Colorectal Cancer Treated in Routine Clinical Practice. Clin Colorectal Cancer. 2016;15:381-388.

51. Petit E, Milano G, Levi F, et al. Circadian rhythm-varying plasma concentration of 5fluorouracil during a five-day continuous venous infusion at a constant rate in cancer patients. Cancer Res. 1988;48:1676-1679.

52. Levi FA, Zidani R, Vannetzel JM, et al. Chronomodulated versus fixed-infusion-rate delivery of ambulatory chemotherapy with oxaliplatin, fluorouracil, and folinic acid (leucovorin) in patients with colorectal cancer metastases: a randomized multiinstitutional trial. J Natl Cancer Inst. 1994;86:1608-1617. 
53. Jacobs BA, Deenen MJ, Pluim D, et al. Pronounced between-subject and circadian variability in thymidylate synthase and dihydropyrimidine dehydrogenase enzyme activity in human volunteers. Br J Clin Pharmacol. 2016;82:706-716.

54. Giacchetti S, Bjarnason G, Garufi C, et al. European Organisation for Research, Treatment of Cancer Chronotherapy Group. Phase III trial comparing 4-day chronomodulated therapy versus 2-day conventional delivery of fluorouracil, leucovorin, and oxaliplatin as first-line chemotherapy of metastatic colorectal cancer: the European Organisation for Research and Treatment of Cancer Chronotherapy Group. J Clin Oncol. 2006;24:3562-3569.

55. Milano G, Etienne MC. [Evolution from pharmacokinetics to pharmacogenetics. The example of 5-fluorouracil]. Rev Med Interne. 1994;15:287-291.

56. Thyss A, Milano G, Renee N, et al. Clinical pharmacokinetic study of 5-FU in continuous 5-day infusions for head and neck cancer. Cancer Chemother Pharmacol. 1986;16:64-66.

57. Kaldate RR, Haregewoin A, Grier CE, et al. Modeling the 5-fluorouracil area under the curve versus dose relationship to develop a pharmacokinetic dosing algorithm for colorectal cancer patients receiving FOLFOX6. Oncologist. 2012;17:296-302.

58. Kline CL, Schiccitano A, Zhu J, et al. Personalized dosing via pharmacokinetic monitoring of 5-fluorouracil might reduce toxicity in early- or late-stage colorectal cancer patients treated with infusional 5-fluorouracil-based chemotherapy regimens. Clin Colorectal Cancer. 2014;13:119-126.

59. Salman D, Barton S, Nabhani-Gebara S. Effect of environmental conditions on performance of elastomeric pumps. Am J Health Syst Pharm. 2013;70:1100.

60. Etienne MC, Lagrange JL, Francois E, et al. Portable pumps in cancer chemotherapy: how to deal with marked fluctuations in 5-fluorouracil blood concentrations. Eur $\mathrm{J}$ Cancer. 1995;31A:2414-2415. 
61. Boisdron-Celle M, Le Guellec C, Suivi Therapeutique Pharmacologique de la Societe Francaise de Pharmacologie et de T. [Therapeutic drug monitoring of 5-fluorouracil after its administration in high-dose protocols]. Therapie. 2010;65:171-176.

62. Murphy RF, Balis FM, Poplack DG. Stability of 5-fluorouracil in whole blood and plasma. Clin Chem. 1987;33:2299-2300.

63. Gamelin E, Bouil AL, Boisdron-Celle M, et al. Cumulative pharmacokinetic study of oxaliplatin, administered every three weeks, combined with 5-fluorouracil in colorectal cancer patients. Clin Cancer Res. 1997;3:891-899.

64. Deng P, Ji C, Dai X, et al. Simultaneous determination of capecitabine and its three nucleoside metabolites in human plasma by high performance liquid chromatographytandem mass spectrometry. J Chromatogr B Analyt Technol Biomed Life Sci. 2015;989:71-79.

65. Montange D, Berard M, Demarchi M, et al. An APCI LC-MS/MS method for routine determination of capecitabine and its metabolites in human plasma. J Mass Spectrom. 2010;45:670-677.

66. Chavani O, Jensen BP, Strother RM, et al. Development, validation and application of a novel liquid chromatography tandem mass spectrometry assay measuring uracil, 5,6dihydrouracil, 5-fluorouracil, 5,6-dihydro-5-fluorouracil, alpha-fluoro-betaureidopropionic acid and alpha-fluoro-beta-alanine in human plasma. J Pharm Biomed Anal. 2017; 142:125-135

67. Beumer JH, Boisdron-Celle $\mathrm{M}$, Clarke W, et al. Multicenter evaluation of a novel nanoparticle immunoassay for 5-fluorouracil on the Olympus AU400 analyzer. Ther Drug Monit. 2009;31:688-694. 
68. Becker R, Hollenbeak CS, Choma A, et al. Cost-Effectiveness of Pharmacokinetic Dosing of 5-Fluorouracil in Metastatic Colorectal Cancer in the United Kingdom. Value Health. 2013;16:A139-A139.

69. Goldstein DA, Chen Q, Ayer T, et al. Cost effectiveness analysis of pharmacokineticallyguided 5-fluorouracil in FOLFOX chemotherapy for metastatic colorectal cancer. Clin Colorectal Cancer. 2014;13:219-225.

70. Beumer JH, Chu E, Allegra C, et al. Therapeutic Drug Monitoring in Oncology: IATDMCT Recommendations for 5-Fluorouracil Therapy. Clin Pharmacol Ther. 2018.

•• Extensive literature review performed by a working group of the IATDMCT which strongly recommended TDM for the management of 5-FU therapy 
Table 1: Studies demonstrating interest of 5-FU therapeutic drug monitoring

\begin{tabular}{|c|c|c|c|c|}
\hline \multicolumn{5}{|c|}{ Retrospective studies } \\
\hline $\begin{array}{l}\text { (Saam J et } \\
\text { al, } \\
2011)[7]\end{array}$ & $\begin{array}{l}\text { Colorectal } \\
\text { cancer } \\
\mathrm{N}=357\end{array}$ & $\begin{array}{l}\text { FLOFIRI and } \\
\text { FOLFOX } 6 \\
2400 \mathrm{mg} / \mathrm{m}^{2} 46 \mathrm{~h} \\
\text { infusion }\end{array}$ & $\begin{array}{l}\text { 5-FU AUC target } \\
\text { range : } 20-24 \\
\text { mg.h/L }\end{array}$ & $\begin{array}{l}\text { Wide range of 5-FU AUC value, with } 21 \% \text { in the target range by } \\
\text { the first measurement. } \\
\text { in a cohort of } 64 \text { patients with } 4 \text { sequential samples, number of } \\
\text { patients in the target range was } 4.8 \% \text { at initial sample and } 37.1 \% \text { by } \\
\text { the fourth measurement }\end{array}$ \\
\hline $\begin{array}{l}\text { (Wihlm J } \\
\text { et al, } \\
1993)[46]\end{array}$ & $\begin{array}{l}\text { Head \& } \\
\text { neck } \\
\text { cancer } \\
\mathrm{N}=14\end{array}$ & $\begin{array}{l}\text { 5-FU-Cisplatine : } \\
5 \text { days continous IV } \\
\text { infusion of 5-FU } \\
1000 \mathrm{mg} / \mathrm{m} 2 / \text { day }\end{array}$ & & $\begin{array}{l}\text { Pharmacokinetic follow-up of 5-FU reduced significantly } \\
\text { haematological and/or digestive tract toxicity ( } 47 \text { to } 33 \% \text { ) }\end{array}$ \\
\hline $\begin{array}{l}\text { (Kline et } \\
\text { al, } \\
2011)[47]\end{array}$ & $\begin{array}{l}\text { Colorectal } \\
\text { cancer } \\
\mathrm{n}=21\end{array}$ & $\begin{array}{l}\text { FOLFOX6 } \\
\text { FOLFOX6 + Avastin } \\
\text { FOLFOX4 } \\
\text { FOLFIRI }\end{array}$ & $\begin{array}{l}\text { 5-FU AUC target } \\
\text { range: } 20-24 \\
\text { mg.h/L }\end{array}$ & $\begin{array}{l}\text { Large variation of } 5-\mathrm{FU} \text { in cycle } 1.2 / 3 \text { of patients achieved AUC } \\
\text { range target with } 0-2 \text { dose adjustments. } 1 / 3 \text { patients needed more } \\
\text { than } 3-4 \text { dose-adjustments to reach the AUC range target }\end{array}$ \\
\hline $\begin{array}{l}\text { (Braiteh et } \\
\text { al, } \\
2014)[10]\end{array}$ & $\begin{array}{l}\text { colorectal } \\
\text { cancer } \\
\mathrm{n}=380\end{array}$ & $\begin{array}{l}\mathrm{mFOLFOX6}: \\
\text { bolus } 400 \mathrm{mg} / \mathrm{m}^{2}+ \\
2400 \mathrm{mg} / \mathrm{m}^{2} 46 \mathrm{~h} \\
\text { infusion }\end{array}$ & $\begin{array}{l}\text { 5-FU AUC } \\
\text { range : } \\
20-30 \mathrm{mg} .\end{array}$ & $\begin{array}{l}62 \% \text { of the patients at the first sample were outside the 5-FU AUC } \\
\text { target range (50\% below and } 12 \% \text { beyond). To reach the target } \\
\text { range of AUC, } 5 \text {-FU was decreased in } 43 \% \text { of the patients who } \\
\text { were above the range and increased in } 52 \% \text { of the patients who } \\
\text { were below the range }\end{array}$ \\
\hline \multicolumn{5}{|c|}{ Prospectives studies } \\
\hline $\begin{array}{l}\text { (Santini J } \\
\text { et al, } \\
1989)[48]\end{array}$ & $\begin{array}{l}\text { Head \& } \\
\text { neck } \\
\text { cancer } \\
\mathrm{n}=170\end{array}$ & $\begin{array}{l}\text { 5-FU-Cisplatine : } \\
5 \text { days continous IV } \\
\text { infusion } \\
1000 \mathrm{mg} / \mathrm{m}^{2} / \text { day } \\
(\mathrm{n}=81),\end{array}$ & $\begin{array}{l}\text { target } \mathrm{AUC}_{0-105 \mathrm{~h}} \\
\text { of } 15 \mathrm{mg} \cdot \mathrm{h} / \mathrm{L}\end{array}$ & $\begin{array}{l}\text { Dose adjustment to reach the target range of 5-FU AUC allowed to } \\
\text { reduce moderate and severe 5-FU toxicities from } 20 \% \text { to } 12.4 \% \\
\text { while increasing therapeutic response from } 31 \% \text { to } 47 \% \text {. }\end{array}$ \\
\hline $\begin{array}{l}\text { (Fety et al, } \\
1998)[41]\end{array}$ & $\begin{array}{l}\text { Head \& } \\
\text { neck } \\
\text { cancer } \\
\mathrm{n}=122\end{array}$ & $\begin{array}{l}\text { Fixed dose arm : } \\
4000 \mathrm{mg} / \mathrm{m}^{2} / 96 \text { hours } \\
\text { infusion } \\
\text { Adapted arm : dose } \\
\text { adaptation from }\end{array}$ & $\begin{array}{l}\text { AUC limits } \\
\text { defining a } \\
\text { dose modification } \\
\text { were } \mathrm{AUC}_{0-48}>13 \\
\text { mg.h } / \mathrm{L} \text { or }<7,2\end{array}$ & $\begin{array}{l}\text { severe adverse events (neutropenia, thrombopenia and mucosis) } \\
\text { were significantly less frequent in the TDM-guided arm }\end{array}$ \\
\hline
\end{tabular}




\begin{tabular}{|c|c|c|c|c|}
\hline & & $\begin{array}{l}\text { cycle } 2 \text { depending on } \\
\text { cycle } 1 \mathrm{AUC}_{0-48 \mathrm{~h}}\end{array}$ & mg.h/L & \\
\hline $\begin{array}{l}\text { (Gamelin } \\
\text { et al, } \\
1998)[49]\end{array}$ & $\begin{array}{l}\text { métastatic } \\
\text { colorectal } \\
\text { cancer } \\
\mathrm{n}=40\end{array}$ & $\begin{array}{l}\text { Initial dose } 1000 \\
\mathrm{mg} / \mathrm{m}^{2} / 8 \text { hours, } \\
\text { weekly }\end{array}$ & $\begin{array}{l}\text { 5-FU dose } \\
\text { adjustment } \\
\text { algorithm } \\
\text { according to } \\
\text { plasma levels at } \\
\text { previous cycle } \\
\end{array}$ & $\begin{array}{l}\text { First study demonstrating benefit of 5-FU dose adaptation based on } \\
5 \text {-FU plasma level }\end{array}$ \\
\hline $\begin{array}{l}\text { (Ychou et } \\
\text { al, 2003) } \\
{[37]}\end{array}$ & $\begin{array}{l}\text { Metastatic } \\
\text { colorectal } \\
\text { cancer } \\
\mathrm{n}=53\end{array}$ & $\begin{array}{l}\text { LV5-FU2 } \\
400 \mathrm{mg} / \mathrm{m}^{2} / \text { day } \\
\text { Bolus and } 600 \\
\mathrm{mg} / \mathrm{m}^{2}, 22 \mathrm{~h} \text { infusion, } \\
2 \text { days. }\end{array}$ & $\begin{array}{l}\text { 5-FU AUC target: } \\
20 \text { mg.h/L } \\
\text { Dose adaptation } \\
\text { from cycle } 2 \\
\text { depending on } \\
\text { cycle } 15 \text {-FU AUC }\end{array}$ & $\begin{array}{l}87 \% \text { of patients had a 5-FU dose increase at cycle } 2 \text {. médian dose } \\
\text { increase factor was } 1,28 \\
\text { dose adjustments to reach an AUC }>20 \mathrm{mg} . \mathrm{h} / \mathrm{L} \text { and an objective } \\
\text { response was obtained in } 37 \% \text { of patients with a } 2 \text {-year overall } \\
\text { survival of } 32 \% \text { and a favorable safety profile }\end{array}$ \\
\hline $\begin{array}{l}\text { (Capitain et } \\
\text { al, } \\
2012)[35]\end{array}$ & $\begin{array}{l}\text { Metastatic } \\
\text { colorectal } \\
\text { cancer } \\
\mathrm{n}=118\end{array}$ & $\begin{array}{l}\text { FOLFOX : } \\
400 \mathrm{mg} / \mathrm{m}^{2} \text { bolus and } \\
2500 \mathrm{mg} / \mathrm{m}^{2}, 46 \mathrm{~h} \\
\text { infusion }\end{array}$ & $\begin{array}{l}\text { Target 5-FU AUC } \\
{[20-25 \mathrm{mg} \cdot \mathrm{h} / \mathrm{L}]}\end{array}$ & $\begin{array}{l}\text { TDM allowed increasing overall duration survival while } \\
\text { dramatically decreasing grade } 3 \text { and } 4 \text { adverse events }\end{array}$ \\
\hline $\begin{array}{l}\text { (Patel et al, } \\
2014)[34]\end{array}$ & $\begin{array}{l}\text { Metastatic } \\
\text { colorectal } \\
\text { cancer } \\
\mathrm{n}=70\end{array}$ & $\begin{array}{l}\text { mFOLFOX6 : } \\
\text { bolus } 400 \mathrm{mg} / \mathrm{m}^{2}+ \\
2400 \mathrm{mg} / \mathrm{m}^{2} 46 \mathrm{~h} \\
\text { infusion }\end{array}$ & $\begin{array}{l}\text { Target 5-FU AUC } \\
{[20-25 \mathrm{mg} . \mathrm{h} / \mathrm{L}]}\end{array}$ & $\begin{array}{l}\text { PK-guided 5-FU dosing resulted in significantly fewer underdosed } \\
\text { patients and less gastrointestinal toxicity }\end{array}$ \\
\hline $\begin{array}{l}\text { (Wilhem et } \\
\text { al, 2016) } \\
{[50]}\end{array}$ & $\begin{array}{l}\text { Metastatic } \\
\text { colorectal } \\
\text { cancer } \\
\mathrm{N}=75\end{array}$ & $\begin{array}{l}\text { AIO, FOLFOX6 or } \\
\text { FUFOX }\end{array}$ & $\begin{array}{l}\text { Target 5-FU AUC } \\
{[20-30 \mathrm{mg} \cdot \mathrm{h} / \mathrm{L}]}\end{array}$ & $\begin{array}{l}\text { 5-FU dose adaptation based on 5-FU AUC level resulted in } \\
\text { improved 5-FU exposure and a lower incidence of grade 3-4 5-FU- } \\
\text { related toxicities }\end{array}$ \\
\hline $\begin{array}{l}\text { (Gamelin } \\
\text { et al, 2008) } \\
{[15]}\end{array}$ & $\begin{array}{l}\text { Metastatic } \\
\text { colorectal } \\
\text { cancer } \\
\mathrm{N}=208\end{array}$ & $\begin{array}{l}1500 \mathrm{~m}^{2} / 8 \text { hours, } \\
\text { weekly }\end{array}$ & $\begin{array}{l}\text { Target 5-FU AUC } \\
{[20-25 \mathrm{mg} . \mathrm{h} / \mathrm{L}]}\end{array}$ & $\begin{array}{l}\text { 5-FU dose adaptation based on } 5 \text {-FU AUC level resulted in } \\
\text { improved objective response rate, a trend to higher survival rate, } \\
\text { and fewer grade } 3 / 4 \text { toxicities }\end{array}$ \\
\hline
\end{tabular}


Table 2: Practical considerations for 5-FU TDM in daily clinical practice

\section{Administration routes}

Constant flow perfusion (avoid gravity diffusers)

First dose must be adapted to DPD phenotype or DPYP genotype

Sampling procedures

During the first and subsequent treatment cycles (at least the $2^{\text {nd }}$ and the $3^{\text {rd }}$ )

A single sample.

$3 \mathrm{~mL}$ blood sample collected in heparinized tube, without separator gel

At least 4 hours after the start of the perfusion

In the morning between 8 and 10 a.m.

Pre-analytical constraints

centrifugation maximally $30 \mathrm{~min}$ after sampling or add a stabilizer reagent to the blood sample just after sampling (maximal delay before centrifugation: 24 hours)

Conservation before analysis: $4^{\circ} \mathrm{C}$ maximally $48 \mathrm{~h}$ or $-20^{\circ} \mathrm{C}$ for a longer delay

5-FU doses adjustment as a function of 5-FU AUC calculated during the previously cycle of treatment, according to an algorithm modified from Gamelin et al. [15] et Kaldate et al. [57]

\begin{tabular}{|c|l|}
\hline AUC (mg .h/L) & $5-\mathrm{FU}$ dose adjustment (+/- \% of previous dose) \\
\hline$>40$ & $-30 \%$ \\
\hline $37-39$ & $-25 \%$ \\
\hline $34-36$ & $-20 \%$ \\
\hline $30-33$ & $-10 \%$ \\
\hline $20-29$ & Unchanged \\
\hline $17-19$ & $+10 \%$ \\
\hline $14-16$ & $+20 \%$ \\
\hline 8 à 13 & $+25 \%$ \\
\hline$<8$ & $+30 \%$ \\
\hline
\end{tabular}

AUC calculation: Concentration $(\mathrm{mg} / \mathrm{L}) \mathrm{x}$ perfusion time $(\mathrm{h})$ 
Figure 1

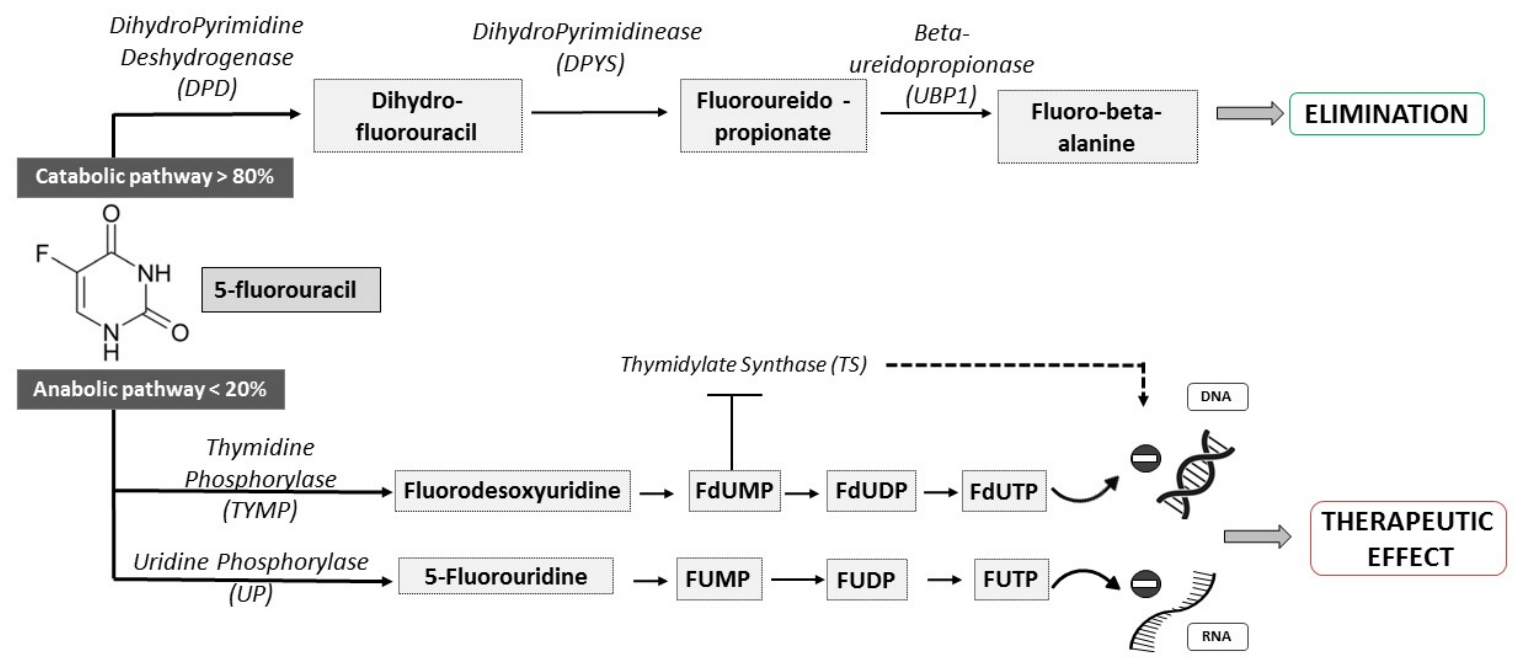

Figure 2

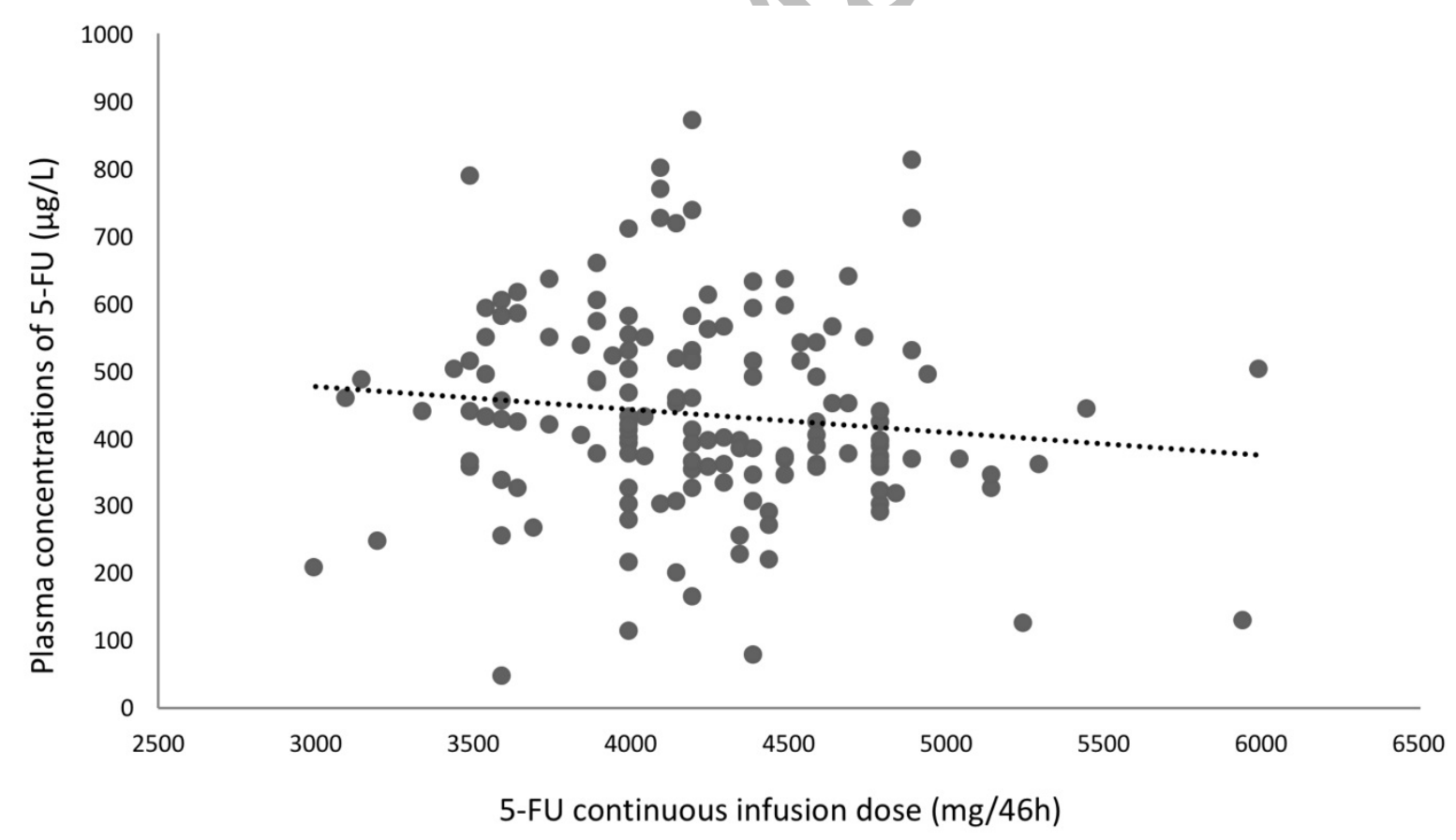

